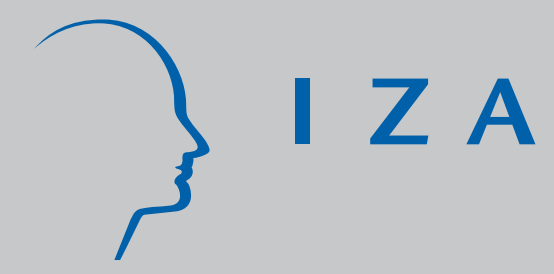

IZADP No. 2366

Extension of Labor Contracts and Optimal Backpay

Leif Danziger

October 2006 


\title{
Extension of Labor Contracts and Optimal Backpay
}

\author{
Leif Danziger \\ Ben Gurion University, \\ Central European University \\ and IZA Bonn
}

\section{Discussion Paper No. 2366 \\ October 2006}

\author{
IZA \\ P.O. Box 7240 \\ 53072 Bonn \\ Germany \\ Phone: +49-228-3894-0 \\ Fax: +49-228-3894-180 \\ E-mail: iza@iza.org
}

\begin{abstract}
Any opinions expressed here are those of the author(s) and not those of the institute. Research disseminated by IZA may include views on policy, but the institute itself takes no institutional policy positions.

The Institute for the Study of Labor (IZA) in Bonn is a local and virtual international research center and a place of communication between science, politics and business. IZA is an independent nonprofit company supported by Deutsche Post World Net. The center is associated with the University of Bonn and offers a stimulating research environment through its research networks, research support, and visitors and doctoral programs. IZA engages in (i) original and internationally competitive research in all fields of labor economics, (ii) development of policy concepts, and (iii) dissemination of research results and concepts to the interested public.
\end{abstract}

IZA Discussion Papers often represent preliminary work and are circulated to encourage discussion. Citation of such a paper should account for its provisional character. A revised version may be available directly from the author. 
IZA Discussion Paper No. 2366

October 2006

\section{ABSTRACT \\ Extension of Labor Contracts and Optimal Backpay}

This paper explains why a union and a firm might settle on a contract duration that may later be extended and characterizes the optimal backpay for the holdout period. It is shown that the choice between concluding a shorter contract that may be extended and immediately concluding a longer contract depends on the prevalence of the different types of uncertainty in the economy. It is also shown that the optimal backpay reduces the negative impact of nominal uncertainty on a worker's real income, but increases the worker's exposure to idiosyncratic uncertainty.

JEL Classification: J41

Keywords: contract extension, contract duration, holdout, backpay, indexation

Corresponding author:

Leif Danziger

Department of Economics

Ben Gurion University of the Negev

Beer-Sheva 84105

Israel

E-mail: danziger@bgu.ac.il 


\section{Introduction}

There is frequently a lengthy holdout period between the expiration date of a collective agreement and the time a new contract is signed. ${ }^{1} \quad$ Usually, the old agreement is legally extended during the holdout, with its terms remaining binding for both the workers and the employer until a new contract has been signed. The exception is if the parties reach a bargaining impasse and work stoppages occur due to strikes or lockouts.

Various theories have been proposed to explain these lengthy holdout periods. Cramton and Tracy (1992) suggest that unions use holdouts as a cheap substitute for strikes to elicit information about firms' profitability, while Gu and Kuhn (1998) regard holdouts as a negotiation tactic that makes it possible to observe contract settlements for other bargaining pairs. Danziger and Neuman (2005) view delayed renewals as a means of reducing risks faced by workers. ${ }^{2} \quad$ All these theories take the duration of the expired contract as given when explaining the delay in reaching a new agreement. As such, they ignore an apparent paradox: Since the expired contract is legally extended during the delay, would it not have been optimal to originally negotiate a longer contract duration? Or to put it differently, why would a longer duration not be preferable to a shorter duration that is later extended?

In the same vein, theoretical models of contract duration are incomplete in that they determine a "fixed" contract duration, while completely ignoring the fact that extensions may significantly increase the effective contract duration and make it de facto state-dependent (Gray, 1978; Dye, 1985; Harris and Holmstrom, 1987; and Danziger, 1988). The same is true of empirical analyses of contract durations which likewise neglect to take extensions into account (Christofides and Wilton, 1983; Ehrenberg et al., 1984; Vroman, 1989; Christofides, 1990; Murphy, 1992 and 2000; Wallace and Blanco, 1991; Wallace, 2001; Rich and Tracy, 2004; and Christofides and Peng, 2006).

The purpose of the present paper is to overcome these shortcomings of the existing

\footnotetext{
${ }^{1}$ In the U.S. the holdout incidence is $47 \%$ and the average holdout is 63 days (Cramton and Tracy, 1992); in the Netherlands the holdout incidence is $100 \%$ and the average holdout is 7-8 months (van Ours and van de Wijngaert, 1996); in Canada the holdout incidence is $81 \%$ and the average holdout is 80 days (Gu and Kuhn, 1998); and in Israel the holdout incidence is $86 \%$ and the average holdout is 213 days (Danziger and Neuman, 2005).

${ }^{2}$ See Cramton and Tracy (1994), Holden $(1994,1997)$, van Ours (1999), and Houba and Bolt (2000) for further analyses.
} 
literature by presenting a model in which it may be optimal for a union and an employer to negotiate a short contract duration even though both sides know that the contract might later get extended. The theoretical framework follows the implicit-contract approach by emphasizing that a contract extension can be beneficial if it helps smoothen the impact of unforeseen shocks on a worker's real income. ${ }^{3}$ The model has two periods and two goods. In the first period there is no uncertainty, but in the second period the economy may be hit by four types of shocks: a real shock that is the same in all firms and affects the productivities of both goods equally; a relative shock that is the same in all firms, but affects the productivities of the two goods differently; an idiosyncratic shock that is firm specific and affects the productivities of both goods equally in a particular firm; and a nominal shock that affects the prices of the goods equally, but leaves the productivities unchanged.

In the model, a union and an employer may conclude a short contract which covers the first period, but that can be extended into the second period. During an extension, workers continue to be employed and paid according to the old contract. The new contract for the second period, when eventually concluded, may retroactively adjust the workers' pay during the extension. The retroactive adjustment need not, however, be complete. As part of the decision to extend the contract, the two sides may implicitly agree on a backpay function that specifies how the backpay will depend on the gap between the real wage in the new contract and the real wage that was paid according to the old contract during the extension. On the other hand, instead of a short contract, the union and the employer may conclude a long contract which covers both periods. In order not to make the preference for an extended short contract a foregone conclusion, the model allows the second-period wage in a long contract to be indexed to the price level.

We show that the choice between a short contract that can be extended and a long contract is independent of the union's and the firm's bargaining powers and depends on the benefit of backpay relative to the benefit of a long contract. Thus, settling on a short

${ }^{3}$ An implicit contract is enforced by the knowledge that worker morale is fragile and apt to deteriorate quickly if workers feel that they are treated unfairly. This is supported by evidence in Fehr and Falk (1999) who show that a firm correctly anticipates that workers will reciprocate what they perceive as fair behavior but will act defiantly if they feel slighted. Nevertheless, there is a limit to how much the real wage can be shifted away from a worker's marginal product without provoking one of the parties to renege on an implicit agreement (e.g., by the workers quitting or the firm laying off workers). The model therefore assumes that the economic fluctuations do not reach a magnitude that would cause the implicit contract to break down. 
contract duration that can be extended is sometimes preferable to immediately settling on a longer duration. It will be demonstrated that there exist combinations of the different types of uncertainty for which the two contract forms are equally desirable. At higher levels of real or idiosyncratic uncertainty, a long contract will Pareto dominate, since it provides better insurance for a worker's real income against these risks. However, at higher levels of relative or nominal uncertainty, a short contract that can be extended will Pareto dominate, since it lets a worker benefit as much as possible from relative-price changes and is better at insuring a worker's real income against nominal risk.

Since the retroactive adjustment of the workers' pay affects the attractiveness of a contract extension, we also characterize the optimal backpay for the extension period. It is shown that the optimal backpay is independent of real and relative shocks, and constitutes a compromise between the first-best full backpay in the case of nominal shocks, and the first-best no backpay in the case of idiosyncratic shocks. As a result, workers get to shoulder some of the idiosyncratic uncertainty in exchange for a lessening of the impact of nominal uncertainty, causing the optimal backpay to increase in the gap between the new real wage and what was paid during the extension.

The theoretical approach in this paper receives empirical support from the evidence in Cramton and Tracy (1994) that the incidence of delay increased from the 1970s to the 1980s, during which time the nominal uncertainty became more important relative to the real uncertainty, and from the finding in Danziger and Neuman (2005) that the incidence of delay is higher for shorter contracts and increases with nominal uncertainty and decreases with real uncertainty. In contrast, if unions were mainly using delays to obtain information about a firm's profitability - either because it is a cheaper industrial action than a strike, or because it gives the union more time to observe settlements in other firms - then the value of delay would increase with real uncertainty. In that case, a higher rather than lower delay incidence would have been associated with increased real uncertainty. Support for the present theory is also provided by the empirical literature on contract duration that finds that contract duration decreases with nominal uncertainty (e.g., Christofides, 1990) and increases with real uncertainty (e.g., Wallace and Blanco, 1991). 


\section{The Model}

Consider a two-period economy with workers and firms. The workers consume a perishable good denoted by $x$, and are risk averse with logarithmic utility functions. The employers, who own the firms, are concerned with a different good denoted by $y$. This good may be interpreted as an investment good, or as the employers' consumption good that due to the Engel-curve effect (employers being wealthier than workers) is different from the workers' consumption good. ${ }^{4}$ The employers are risk neutral.

Each worker supplies one unit of labor to a particular firm in each period, and all firms hire the same number of workers, $L$, and have access to the same production technology. In the first period there is no uncertainty and the production possibilities in each firm is given by $x+y=1$.

The productivity in the second period is uncertain, as the economy is exposed to three types of productivity shocks between the first and second period: (1) an aggregate real shock $\alpha$ that changes the production possibilities to $x+y=1+\alpha$ in all firms; (2) an aggregate relative shock $\beta$ that changes the production possibilities to $x /(1+\beta)+y=1$ in all firms; (3) an idiosyncratic shock $\delta$ that differs among firms and changes the production possibilities in a firm to $x+y=1+\delta$. The average (over firms) of the realizations of $\delta$ is zero, so idiosyncratic shocks have no economy-wide effect on productivity. In addition to the productivity shocks, there is also a nominal shock $\nu$ that changes the inverse of the income velocity of money by a factor $1+\nu$.

The probability that a real shock will occur is denoted by $\phi_{\alpha}$, that a relative shock will occur by $\phi_{\beta}$, that an idiosyncratic shock will occur by $\phi_{\delta}$, and that a nominal shock will occur by $\phi_{\nu}$. Each type of shock occurs with positive probability, and the mean of a shock is zero. It is assumed, for simplicity, that at most one type of shock occurs and that the different types of shocks have the same symmetric and nondegenerate distribution.

Let $p_{i}$ and $q_{i}$ denote the prices of $x$ and $y$ in period $i=1,2$, and $X_{i}$ and $Y_{i}$ denote the aggregate production of $x$ and $y$ in period $i$. Prices are determined by a velocity equation, which in the first period is $p_{1} X_{1}+q_{1} Y_{1}=K$, where $K$ is a constant. The unitary marginal rate of transformation between the goods implies that $p_{1}=q_{1}$, and therefore that $p_{1}=$

\footnotetext{
${ }^{4}$ If the employer is in the public sector, $y$ may be a public good.
} 
$q_{1}=K / F$, where $F$ is the number of firms. In the second period, the velocity equation is $p_{2} X_{2}+q_{2} Y_{2}=K$ if there is no nominal shock, and $p_{2} X_{2}+q_{2} Y_{2}=K /(1+\nu)$ if there is a nominal shock. Accordingly, in case of a real shock, where the production possibilities of both goods change by a factor of $1+\alpha$ in all firms, the prices become $p_{2}=q_{2}=K /[F(1+\alpha)]$; in case of a relative shock, where the production possibilities of $x$ change by a factor of $1+\beta$ in all firms, while the production possibilities of $y$ remain unchanged, the prices become $p_{2}=K /[F(1+\beta)]$ and $q_{2}=K / F$; in case of idiosyncratic shocks, where the overall productivity in the economy is unaffected, the prices remain unchanged and $p_{2}=q_{2}=K / F$; in case of a nominal shock, where the income velocity changes by a factor of $1 /(1+\nu)$, the prices become $p_{2}=q_{2}=K /[F(1+\nu)]$.

At the beginning of the first period, the union representing the workers employed in a particular firm negotiates a labor contract with that firm. The contract may be short and cover the first period only, in which case the union and the firm will subsequently negotiate a new short contract for the second period. If a short contract is concluded, the contract may later be extended and the negotiation of the next contract postponed to well into the second period. In that case, the workers will receive a backpay that depends on how the real wage in the new contract differs from the real wage paid during the extension of the old contract. Alternatively, at the beginning of the first period, the union and the firm may conclude a long contract covering both periods. In a long contract, the nominal wage in the second period is indexed to the price level, and the real wage in the second period therefore depends on how the price level evolves.

Ideally, one would like to explicitly model the bargaining process between unions and firms in order to derive, for both contract forms, the division of a firm's output as a function of the parties' bargaining powers. However, this is beyond the scope of the present paper, and we instead parameterize the distribution of bargaining powers by the share $c \in(0,1 / L)$ of a firm's output that each worker can expect to receive. Thus, for a given $c$, we first determine the characteristics of each contract form and calculate the corresponding constrained Pareto frontier consisting of the expected utility for workers and the expected real profit for the employer. We then compare the constrained Pareto frontiers for the two contract forms and establish when one of the contract forms dominates the other for all values of $c$. 


\section{Extended Short Contract}

Suppose that a short contract is concluded. In the first period, a firm's production possibilities are given by $x+y=1$, so the labor contract sets the nominal wage equal to $c p_{1}$. The real wage is therefore $c$, and a worker's utility from the first period is $\ln c .^{5}$ The employer keeps the remaining $1-c L$ units of $y$ after the workers have been paid.

Suppose further that before the contract expires at the end of the first period, and hence before the second-period uncertainty is resolved, the union agrees with the firm to delay the contract's renewal and extend the current contract to the end of the second period. Accordingly, the nominal wage remains equal to $c p_{1} \cdot{ }^{6}$ The workers' resultant real wage during the extension will be $c p_{1} / p_{2}$, which depends on the type and size of the shock hitting the economy as follows: it will be $c(1+\alpha)$ for a real shock; $c(1+\beta)$ for a relative shock; $c(1+\nu)$ for a nominal shock; and $c$ for an idiosyncratic shock or no shock at all.

The union and the firm also agree that when the new contract is eventually concluded, it will provide a backpay that retroactively adjusts the second-period wage already paid. The expected real value of the backpay is zero. Specifically, the two sides determine an implicit backpay function that describes how the retroactive pay of $x$ will depend on the gap between the real wage in the new contract and the real wage paid during the extension of the old contract. Denoting this gap by $z$, the backpay function is $b(z)$, and the nominal retroactive pay is therefore $p_{1} b(z)$.

In the second period, a firm's production possibilities may change due to the shocks. The real wage in the new contract is therefore $c(1+\alpha)$ if the shock is real, $c(1+\beta)$ if the shock is relative, $c(1+\delta)$ if the shock is idiosyncratic, and $c$ if the shock is nominal or there is no shock. Accordingly, in the case of a real or relative shock, there is no gap between the new real wage and the real wage paid during the extension. The reason is that the real price of $x$ is inversely proportional to the overall productivity, so that the unchanged nominal wage during the contract extension provides a real wage that matches the new production

\footnotetext{
${ }^{5}$ It is assumed, without loss of generality, that a worker does not borrow or lend. It can be shown that with the optimal backpay or indexation, a worker would never want to borrow or lend nominal amounts.

6 This is in accordance with the institutional setting in most countries. In particular, there is normally no wage indexation during an extension. In fact, in Norway it would even be illegal (Holden, 1994). An exception is Israel, where the wage indexation is legislated (Danziger and Neuman, 2005).
} 
possibilities. Thus, a worker's total nominal income in the second period is always $p_{1}[c+b(0)]$, and his total real income is $(1+\alpha)[c+b(0)]$ for a real shock and $(1+\beta)[c+b(0)]$ for a relative shock.

In the case of an idiosyncratic shock, the gap between the new real wage and the real wage paid during the extension is $c \delta$, since productivity changes by a factor of $1+\delta$, while prices remain unchanged. A worker's total nominal income in the second period is $p_{1}[c+b(c \delta)]$, and his total real income is $c+b(c \delta)$.

In the case of a nominal shock, the gap between the new real wage and the real wage paid during the extension is $-c \nu$, since the production possibilities remain unchanged, while the real wage paid during the extension changes to $c(1+\nu)$. A worker's total nominal income in the second period is $p_{1}[c+b(-c \nu)]$, and his total real income is $(1+\nu)[c+b(-c \nu)]$.

Finally, if there is no shock, a worker's total nominal income in the second period is $p_{1}[c+b(0)]$, and his total real income is $c+b(0)$.

When the contract is extended and the backpay function determined, a worker's expected utility from the two periods is

$$
\begin{aligned}
& \ln c+\phi_{\alpha} \underset{\alpha}{\mathrm{E}} \ln \{(1+\alpha)[c+b(0)]\}+\phi_{\beta} \underset{\beta}{\mathrm{E}} \ln \{(1+\beta)[c+b(0)]\}+\phi_{\delta} \underset{\delta}{\mathrm{E}} \ln [c+b(c \delta)] \\
& +\phi_{\nu} \underset{\nu}{\mathrm{E}} \ln \{(1+\nu)[c+b(-c \nu)]\}+\left(1-\phi_{\alpha}-\phi_{\beta}-\phi_{\delta}-\phi_{\nu}\right) \ln [c+b(0)],
\end{aligned}
$$

or, more simply,

$$
\begin{aligned}
& \ln c+\phi_{\alpha} \underset{\alpha}{\mathrm{E}} \ln (1+\alpha)+\phi_{\beta} \underset{\beta}{\mathrm{E}} \ln (1+\beta)+\phi_{\nu} \underset{\nu}{\mathrm{E}} \ln (1+\nu) \\
& +\phi_{\delta} \underset{\delta}{\mathrm{E}} \ln [c+b(c \delta)]+\phi_{\nu} \underset{\nu}{\mathrm{E}} \ln [c+b(-c \nu)]+\left(1-\phi_{\delta}-\phi_{\nu}\right) \ln [c+b(0)] .
\end{aligned}
$$

Since shocks are symmetrically distributed around zero, the nominal shocks $-\nu$ and $\nu$ are equally likely. Hence, $\underset{\nu}{\mathrm{E}} \ln [c+b(-c \nu)]=\underset{\nu}{\mathrm{E}} \ln [c+b(c \nu)]$, and a worker's expected utility is

$$
\begin{aligned}
& \ln c+\phi_{\alpha} \underset{\alpha}{\mathrm{E}} \ln (1+\alpha)+\phi_{\beta} \underset{\beta}{\mathrm{E}} \ln (1+\beta)+\phi_{\nu} \underset{\nu}{\mathrm{E}} \ln (1+\nu) \\
& +\phi_{\delta} \underset{\delta}{\mathrm{E}} \ln [c+b(c \delta)]+\phi_{\nu} \underset{\nu}{\mathrm{E}} \ln [c+b(c \nu)]+\left(1-\phi_{\delta}-\phi_{\nu}\right) \ln [c+b(0)] .
\end{aligned}
$$

This expression can be further simplified by letting $\epsilon$ denote the size of a shock, whatever its type. All shocks have the same distribution, so a worker's expected utility becomes

$$
\ln c+\left(\phi_{\alpha}+\phi_{\beta}+\phi_{\nu}\right) \underset{\epsilon}{\mathrm{E}} \ln (1+\epsilon)+\left(\phi_{\delta}+\phi_{\nu}\right) \underset{\epsilon}{\mathrm{E}} \ln [c+b(c \epsilon)]+\left(1-\phi_{\delta}-\phi_{\nu}\right) \ln [c+b(0)]
$$


Since the employer's expected real cost of the backpay is $b(0)$ if a real or relative shock occurs, $\mathrm{E}_{\delta} b(c \delta)$ if an idiosyncratic shock occurs, $\mathrm{E}_{\nu}[(1+\nu) b(-c \nu)]$ if a nominal shock occurs, and $b(0)$ if there is no shock, the backpay function satisfies

$$
\phi_{\delta} \underset{\delta}{\mathrm{E}} b(c \delta)+\phi_{\nu} \underset{\nu}{\mathrm{E}}[(1+\nu) b(-c \nu)]+\left(1-\phi_{\delta}-\phi_{\nu}\right) b(0)=0
$$

or, by the symmetry of the distribution of the nominal shocks around zero,

$$
\phi_{\delta} \underset{\delta}{\mathrm{E}} b(c \delta)+\phi_{\nu} \underset{\nu}{\mathrm{E}}[(1-\nu) b(c \nu)]+\left(1-\phi_{\delta}-\phi_{\nu}\right) b(0)=0 .
$$

With $\epsilon$ denoting the shock size, the backpay constraint can be written as

$$
\underset{\epsilon}{\mathrm{E}}\left\{\left[\phi_{\delta}+\phi_{\nu}(1-\epsilon)\right] b(c \epsilon)\right\}+\left(1-\phi_{\delta}-\phi_{\nu}\right) b(0)=0
$$

The backpay function maximizes a worker's expected utility (1) subject to (2). Since $\epsilon=z / c$, the unique optimal backpay function $b(z)$ is given by

$$
\begin{gathered}
\frac{\phi_{\delta}+\phi_{\nu}}{c+b(z)}=\lambda\left[\phi_{\delta}+\phi_{\nu}(1-z / c)\right] \quad \text { for all } z, \\
\Leftrightarrow b(z)=\frac{\phi_{\delta}+\phi_{\nu}}{\lambda\left[\phi_{\delta}+\phi_{\nu}(1-z / c)\right]}-c \quad \text { for all } z,
\end{gathered}
$$

where $\lambda$ is a positive constant determined such that the (2) is satisfied. Substituting (3) in (2) shows that $\lambda=1 / c$, implying that the backpay function is

$$
b(z)=c\left[\frac{\phi_{\delta}+\phi_{\nu}}{\phi_{\delta}+\phi_{\nu}(1-z / c)}-1\right] \quad \text { for all } z .
$$

By its very nature, the backpay is a function of the gap between the new real wage and the real wage paid during the extension. The type and size of shocks do not enter the backpay function directly, so realizations of the shocks can affect the backpay only to the extent that they are reflected in $z$.

\subsection{A Digression: The First-Best Real Pay}

In order to understand the expression for the backpay in eq. (4), it is helpful first to digress and characterize the first-best real pay in the second period. Appendix A shows that if the shock is real, idiosyncratic, or nominal, the first-best real pay is independent of the 
realization of the shock and equal to $c$. This is because these shocks do not change relative prices, and all risk can be shifted costlessly from the risk-averse workers to the risk-neutral employer. To achieve the first-best real pay, the real backpay should be $-c \alpha /(1+\alpha)$ if the shock is real, zero if the shock is idiosyncratic, and $-c \nu /(1+\nu)$ if the shock is nominal. If there is no shock, the first-best real pay is also $c$ and there should be no backpay.

On the other hand, Appendix A also shows that if the shock is relative, the first-best real pay equals $c(1+\beta)$. None of the relative risk should be shifted from the workers. The reason is that a relative shock changes relative prices and thereby introduces another consideration, besides that of risk shifting, in the determination of the first-best real pay. Specifically, relative-price changes can be exploited to increase a worker's expected real pay in terms of $x$, for a given expected real pay in terms of $y$, if his real pay exceeds $c(1+\beta)$ when a relative shock is positive (and $p_{2}<1$ ), and is less than $c(1+\beta)$ when a relative shock is negative (and $p_{2}>1$ ). However, the flipside of the worker obtaining a higher expected real income is that his real income is more exposed to relative uncertainty. Accordingly, shifting the relative risk to the employer is costly in terms of foregoing a higher expected real pay, and there is a tradeoff between risk shifting and exploiting the changes in relative prices to increase a worker's expected real income. ${ }^{7}$

Given the logarithmic utility function, in the case of a relative shock the first-best solution is that a worker always be paid $c(1+\beta)$ and thereby carrying all risk stemming from relative uncertainty. It is not desirable to shift some of the worker's risk to the firm by having his real income increase less than proportionally with $1+\beta$ and thereby lower his expected real income. Likewise, it is not desirable to have the worker take on additional risk by having his real income increase more than proportionally with $1+\beta$ in order to increase his expected real income. Thus, in order to achieve the first-best real pay, there should be no backpay if the shock is relative.

\footnotetext{
7 Considering only outcomes with a relative shock: if the real pay were to be constant in terms of $x$ and expected to cost the employer $c$ of $y$, it would be $c / E_{\beta}[1 /(1+\beta)]$, which is less than $c$. In the first-best case, the worker's expected real pay is $c E_{\beta}(1+\beta)=c$.
} 


\subsection{Optimal Backpay: An Interpretation}

Let us return to the backpay function in eq. (4). The backpay does not directly depend on the shock itself, but only on the resulting gap $z$ between the new real wage and what was paid during the extension. If the shock is real or relative, however, the gap is always zero, i.e., $z=0$ for all realizations of $\alpha$ and $\beta$. Since $z$ provides no information about the size of a shock, it cannot be used to condition differential retroactive payments. There is never any backpay, $b(0)=0$, and therefore no risk shifting: Workers carry the whole impact of the uncertain production possibilities, and their real income in the second period is $c(1+\alpha)$ if the shock is real, and $c(1+\beta)$ if the shock is relative. Compared to the first-best, their exposure to risk is inefficient for real shocks, but efficient for relative shocks.

In contrast, if the shock is idiosyncratic or nominal, the gap provides information about the size of the underlying shock and can be used to condition the backpay. In order for the worker's real income to equal the first-best $c$ for any realization of idiosyncratic and nominal shocks, there should be no backpay if the shock is idiosyncratic, and a real backpay of $z /(1-z / c)$ if the shock is nominal. However, these two requirements cannot both be completely satisfied since the backpay can only depend on the size of the gap, and not also on the type of shock that causes the gap.

The optimal backpay function (4) incorporates as much as possible of the two requirements of the first-best outcome in order to minimize the overall impact of the idiosyncratic and nominal uncertainty on a worker's expected utility. This is achieved by the backpay function weighing the two desiderata, while at the same time keeping the total expected real pay equal to $c$ for any realized gap stemming from an idiosyncratic or nominal shock. ${ }^{8}$ As can readily be seen from eq. (4), the backpay always increases with the gap, but the extent of the backpay (i.e., $d b(z) / d z$ ) decreases with the likelihood of an idiosyncratic shock and increases with the likelihood of a nominal shock. Accordingly, the more likely the occur-

\footnotetext{
probability $\phi_{\nu} /\left(\phi_{\delta}+\phi_{\nu}\right)$, for any $z$ the total expected real pay is

$$
\begin{aligned}
& \frac{\phi_{\delta}}{\phi_{\delta}+\phi_{\nu}}[c+b(z)]+\frac{\phi_{\nu}}{\phi_{\delta}+\phi_{\nu}}(1-z / c)[c+b(z)] \\
= & \frac{\phi_{\delta}+\phi_{\nu}(1-z / c)}{\phi_{\delta}+\phi_{\nu}}[c+b(z)] \\
= & c .
\end{aligned}
$$
}

${ }^{8}$ Given the shock is idiosyncratic with conditional probability $\phi_{\delta} /\left(\phi_{\delta}+\phi_{\nu}\right)$, and nominal with conditional 
rence of an idiosyncratic shock and the less likely the occurrence of a nominal shock, for a given gap the backpay is closer to the first-best value of zero for an idiosyncratic shock, and further away from the first-best value of $z /(1-z / c)$ for a nominal shock. That is, less of the idiosyncratic uncertainty and more of the nominal uncertainty fall on the workers. ${ }^{9}$

\subsection{The Constrained Pareto Frontier with Contract Extension}

A worker's expected utility from the two periods with an extended short contract and the optimal backpay function depends on the union's and firm's bargaining powers as parameterized by the share $c$ of a firm's output that a worker can expect to receive. The expected utility is denoted by $V_{s}(c)$ and obtained by substituting (4) with $z=c \epsilon$ in (1),

$$
V_{s}(c) \equiv 2 \ln c+\left(\phi_{\alpha}+\phi_{\beta}+\phi_{\nu}\right) \underset{\epsilon}{\mathrm{E}} \ln (1+\epsilon)+\left(\phi_{\delta}+\phi_{\nu}\right) \underset{\epsilon}{\mathrm{E}} \ln \left[\frac{\phi_{\delta}+\phi_{\nu}}{\phi_{\delta}+\phi_{\nu}(1-\epsilon)}\right] \text {. }
$$

Due to the symmetry of the distribution of shocks, this expression can also be written as

$$
V_{s}(c)=2 \ln c+\left(\phi_{\alpha}+\phi_{\beta}+\phi_{\nu}\right) \underset{\epsilon}{\mathrm{E}} \ln (1+\epsilon)+\left(\phi_{\delta}+\phi_{\nu}\right) \underset{\epsilon}{\mathrm{E}} \ln \left[\frac{\phi_{\delta}+\phi_{\nu}}{\phi_{\delta}+\phi_{\nu}(1+\epsilon)}\right] .
$$

The first term of $V_{s}(c)$ is what the utility would be if there were no uncertainty and it increases with the union's bargaining strength relative to that of the firm. The second term of $V_{s}(c)$, which is negative, is the loss of expected utility due to uncertainty if the contract had not been extended and the new contract concluded before the realizations of the second-period shocks. ${ }^{10}$ A real, relative, or nominal shock would have a full impact on a worker's utility, while an idiosyncratic shock would have no effect. The third term of $V_{s}(c)$, which is positive, shows the gain of expected utility due to the optimal backpay schedule. It consists of the probability that an idiosyncratic or nominal shock occurs, i.e., $\phi_{\delta}+\phi_{\nu}$, multiplied by the expected gain from the backpay, conditional on such a shock occurring, i.e., $\mathrm{E}_{\epsilon} \ln \left\{\left(\phi_{\delta}+\phi_{\nu}\right) /\left[\phi_{\delta}+\phi_{\nu}(1+\epsilon)\right]\right\}$.

Since the purpose of backpay is to mitigate the impact of nominal uncertainty, the expected gain from the optimal backpay function increases with the nominal uncertainty.

\footnotetext{
9 Since the gap $z$ may be negative, it is possible that the backpay is negative. This could be avoided by assuming that there is enough of an inflationary trend in the income velocity of money that prices always increase. This would also ensure that the wage increases from the first to the second contract. Similarly, in the long contract, it would ensure that the wage indexation always leads to a wage increase.

10 This is equivalent to extending the original contract without provision for backpay.
} 
Backpay does not, however, provide complete insurance against nominal shocks. So in spite of the positive effect of backpay, the overall effect of nominal uncertainty is to reduce the total expected utility from the contract. ${ }^{11}$ Mitigating the impact of nominal uncertainty is attained at the cost of exposing workers to idiosyncratic uncertainty. The expected gain from the optimal backpay function, and hence the total expected utility from the contract, therefore decreases with idiosyncratic uncertainty. ${ }^{12}$ Finally, since the extension cannot relieve real and relative uncertainty, the total expected utility from the contract decreases with the real and relative risk.

The employer's expected real profit from the two periods also depends on the parties' bargaining powers and is $\Pi_{s}(c) \equiv 2-2 c L$. The stronger the union's bargaining power relative to that of the firm, the smaller is $\Pi_{s}(c)$. Consequently, the constrained Pareto frontier with an extended short contract and the optimal backpay function is given by $\left(V_{s}(c), \Pi_{s}(c)\right)$, where $c \in(0,1 / L)$.

\section{Long Contract}

Suppose that at the beginning of the first period, the union and firm negotiate a long contract covering both periods. The contract sets the nominal wage to $w$ for the first period and determines an indexation function $i\left(p_{2} / p_{1}\right)$ that ties changes in the nominal wage between

${ }^{11}$ Formally, the derivative of the expected gain from backpay with respect to $\phi_{\nu}$ is

$$
\underset{\epsilon}{\mathrm{E}}\left[-\ln (1+k \epsilon)+1-\frac{1+\epsilon}{1+k \epsilon}\right],
$$

where $k \equiv \phi_{\nu} /\left(\phi_{\delta}+\phi_{\nu}\right)$. This derivative is positive since it tends to zero as $k$ tends to zero and increases in $k$ (differentiating the derivative with respect to $k$ yields $\left.(1-k) \mathrm{E}_{\epsilon}[\epsilon /(1+k \epsilon)]^{2}>0\right)$.

The derivative of $V_{s}(c)$ with respect to $\phi_{\nu}$ is

$$
\underset{\epsilon}{\mathrm{E}}\left[\ln \left(\frac{1+\epsilon}{1+k \epsilon}\right)+1-\frac{1+\epsilon}{1+k \epsilon}\right],
$$

which is negative, since the internal function is negative whenever $\epsilon \neq 1$.

12 The derivative of the expected gain from backpay, and of $V_{s}(c)$, with respect to $\phi_{\delta}$ is

$$
\underset{\epsilon}{\mathrm{E}}\left[-\ln (1+k \epsilon)+1-\frac{1}{1+k \epsilon}\right]
$$

which is negative, since the internal function is negative whenever $\epsilon \neq 1$. 
the first and second period to innovations in the price index of a worker's consumption. Thus, the nominal wage in the second period will be $w\left[1+i\left(p_{2} / p_{1}\right)\right]$.

Since $p_{2} / p_{1}$ equals $1 /(1+\alpha)$ if the shock is real, $1 /(1+\beta)$ if the shock is relative, $1 /(1+\nu)$ if the shock is nominal, and equals 1 if the shock is idiosyncratic or if there is no shock, a worker's expected utility from a long contract is

$$
\begin{aligned}
& \ln \left(\frac{w}{p_{1}}\right)+\phi_{\alpha} \underset{\alpha}{\mathrm{E}} \ln \left\{\frac{w(1+\alpha)}{p_{1}}\left[1+i\left(\frac{1}{1+\alpha}\right)\right]\right\}+\phi_{\beta} \underset{\beta}{\mathrm{E}} \ln \left\{\frac{w(1+\beta)}{p_{1}}\left[1+i\left(\frac{1}{1+\beta}\right)\right]\right\} \\
& +\phi_{\nu} \underset{\nu}{\mathrm{E}} \ln \left\{\frac{w(1+\nu)}{p_{1}}\left[1+i\left(\frac{1}{1+\nu}\right)\right]\right\}+\left(1-\phi_{\alpha}-\phi_{\beta}-\phi_{\nu}\right) \ln \left\{\frac{w}{p_{1}}[1+i(1)]\right\} .
\end{aligned}
$$

This can be simplified to

$$
2 \ln \left(\frac{w}{p_{1}}\right)+\left(\phi_{\alpha}+\phi_{\beta}+\phi_{\nu}\right) \underset{\epsilon}{\mathrm{E}} \ln \left\{(1+\epsilon)\left[1+i\left(\frac{1}{1+\epsilon}\right)\right]\right\}+\left(1-\phi_{\alpha}-\phi_{\beta}-\phi_{\nu}\right) \ln [1+i(1)] .
$$

Given the bargaining powers of the two sides, the employer's total expected real cost in terms of $y$ of the first- and second-period wages equals $c$ of the production possibilities in the first period plus $c$ of the expected production possibilities in the second period; that is, together $2 c$ units of $y$. Relative prices in the second period are unchanged, except if the shock is relative, in which case the price of $x$ changes, while the price of $y$ is unchanged. Thus, the nominal wage for the first period and the indexation function must satisfy

$$
\begin{aligned}
& \frac{w}{p_{1}}+\phi_{\alpha} \underset{\alpha}{\mathrm{E}}\left\{\frac{w(1+\alpha)}{p_{1}}\left[1+i\left(\frac{1}{1+\alpha}\right)\right]\right\}+\phi_{\beta} \underset{\beta}{\mathrm{E}}\left\{\frac{w}{p_{1}}\left[1+i\left(\frac{1}{1+\beta}\right)\right]\right\} \\
& +\phi_{\nu} \underset{\nu}{\mathrm{E}}\left\{\frac{w(1+\nu)}{p_{1}}\left[1+i\left(\frac{1}{1+\nu}\right)\right]\right\}+\left(1-\phi_{\alpha}-\phi_{\beta}-\phi_{\nu}\right) \frac{w}{p_{1}}[1+i(1)]=2 c .
\end{aligned}
$$

This can be simplified to

$$
\frac{w}{p_{1}}\left(1+\underset{\epsilon}{\mathrm{E}}\left\{\left[\left(\phi_{\alpha}+\phi_{\nu}\right)(1+\epsilon)+\phi_{\beta}\right]\left[1+i\left(\frac{1}{1+\epsilon}\right)\right]\right\}+\left(1-\phi_{\alpha}-\phi_{\beta}-\phi_{\nu}\right)[1+i(1)]\right)=2 c .
$$

The long contract consists of a nominal wage for the first period and an indexation function that maximize a worker's expected utility (5) under the constraint (6). The unique optimal long contract therefore satisfies

$$
\frac{2}{w}=\frac{\eta}{p_{1}}\left(1+\underset{\epsilon}{\mathrm{E}}\left\{\left[\left(\phi_{\alpha}+\phi_{\nu}\right)(1+\epsilon)+\phi_{\beta}\right]\left[1+i\left(\frac{1}{1+\epsilon}\right)\right]\right\}+\left(1-\phi_{\alpha}-\phi_{\beta}-\phi_{\nu}\right)[1+i(1)]\right),
$$


and

$$
\frac{\phi_{\alpha}+\phi_{\beta}+\phi_{\nu}}{1+i\left(p_{2} / p_{1}\right)}=\frac{\eta w}{p_{1}}\left(\frac{\phi_{\alpha}+\phi_{\nu}}{p_{2} / p_{1}}+\phi_{\beta}\right) \quad \text { for all } p_{2} / p_{1}
$$

where $\eta$ is a positive constant which is determined so that constraint (6) holds. Substituting (7) in (6) shows that $\eta=1 / c$. Together, (7) and (8) then show that $w=c p_{1}$ and that the indexation formula is

$$
i\left(\frac{p_{2}}{p_{1}}\right)=\frac{\phi_{\alpha}+\phi_{\beta}+\phi_{\nu}}{\left(\phi_{\alpha}+\phi_{\nu}\right) p_{1} / p_{2}+\phi_{\beta}}-1 \quad \text { for all } p_{2} / p_{1} .
$$

Thus, the first-period real wage is equal to $c$. If the shock is real, idiosyncratic, or nominal, it is first-best for the second-period real wage to be insulated from the shock and also be equal to $c$. This is automatically obtained in the case of an idiosyncratic shock where prices are unchanged from the first period, but would require complete wage indexation in the case of a real or nominal shock where prices change. If the shock is relative, it is first-best that the second-period real wage be equal to $c(1+\beta)$. This would require a constant nominal wage; that is, there should be no wage indexation.

The optimal indexation function weighs the advantage of complete indexation in the case of a real or nominal shock against the advantage of no indexation in the case of a relative shock. To minimize the total loss from uncertainty, the wage indexation should be partial, and the expected real pay in the second period be $c$ units of $y$ for any realized $p_{2} / p_{1}$ stemming from a real, relative, or nominal shock. ${ }^{13}$ The extent of indexation (i.e., $\left.\operatorname{di}\left(p_{2} / p_{1}\right) / d\left(p_{2} / p_{1}\right)\right)$ increases with the likelihood of a real and nominal shock, and decreases with the likelihood of a relative shock.

\subsection{The Constrained Pareto Frontier with a Long Contract}

To obtain a worker's expected utility from a long contract with optimal indexation, we substitute $w=c p_{1}$ and the indexation formula with $p_{2} / p_{1}=1 /(1+\epsilon)$ in $(5)$. The expected

\footnotetext{
${ }^{13}$ Given that the conditional probability of a real and nominal shock is $\left(\phi_{\alpha}+\phi_{\nu}\right) /\left(\phi_{\alpha}+\phi_{\beta}+\phi_{\nu}\right)$, and of a relative shock is $\phi_{\beta} /\left(\phi_{\alpha}+\phi_{\beta}+\phi_{\nu}\right)$, for any $p_{2} / p_{1}$ the expected real pay of $y$ in the second period is

$$
\begin{aligned}
& c\left\{\frac{\phi_{\alpha}+\phi_{\nu}}{\phi_{\alpha}+\phi_{\beta}+\phi_{\nu}} \frac{\left[1+i\left(p_{2} / p_{1}\right)\right]}{p_{2} / p_{1}}+\frac{\phi_{\beta}}{\phi_{\alpha}+\phi_{\beta}+\phi_{\nu}}\left[1+i\left(\frac{p_{2}}{p_{1}}\right)\right]\right\} \\
= & c\left\{\frac{\left(\phi_{\alpha}+\phi_{\nu}\right) p_{1} / p_{2}+\phi_{\beta}}{\phi_{\alpha}+\phi_{\beta}+\phi_{\nu}}\left[1+i\left(\frac{p_{2}}{p_{1}}\right)\right]\right\}
\end{aligned}
$$$$
=c \text {. }
$$ 
utility $V_{\ell}(c)$, which depends on the union's and firm's bargaining powers, is

$$
V_{\ell}(c) \equiv 2 \ln c+\left(\phi_{\alpha}+\phi_{\beta}+\phi_{\nu}\right) \underset{\epsilon}{\mathrm{E}} \ln (1+\epsilon)+\left(\phi_{\alpha}+\phi_{\beta}+\phi_{\nu}\right) \underset{\epsilon}{\mathrm{E}} \ln \left[\frac{\phi_{\alpha}+\phi_{\beta}+\phi_{\nu}}{\left(\phi_{\alpha}+\phi_{\nu}\right)(1+\epsilon)+\phi_{\beta}}\right] \text {. }
$$

The first term of $V_{\ell}(c)$ is what the utility of a long contract would be if there were no uncertainty, and it increases with the union's relative bargaining strength. The second term of $V_{\ell}(c)$ is negative and equals the loss of expected utility due to uncertainty if the contract had been unindexed. The third term of $V_{\ell}(c)$ is positive and shows the gain of expected utility from the ameliorating effect of the optimal indexation: the term is the probability that a real, relative, or nominal shock occurs, i.e., $\phi_{\alpha}+\phi_{\beta}+\phi_{\nu}$, multiplied by the gain of expected utility stemming from indexation conditional on one of these shocks occurring, i.e., $\mathrm{E}_{\epsilon} \ln \left\{\left(\phi_{\alpha}+\phi_{\beta}+\phi_{\nu}\right) /\left[\left(\phi_{\alpha}+\phi_{\nu}\right)(1+\epsilon)+\phi_{\beta}\right]\right\}$.

The gain of expected utility from the optimal indexation increases with real and nominal uncertainty, since the objective of indexation is to reduce the repercussions on the real wage from the buffeting of the price level by real and nominal shocks. However, the optimal indexation is only partial, so on the whole, the total expected utility from the contract decreases with real and nominal uncertainty. At the same time, the optimal indexation causes the workers to be overly shielded from relative uncertainty, and therefore to not benefit as much as possible from relative price changes. Hence, the expected gain from indexation and the total expected utility from the contract decrease with relative uncertainty. ${ }^{14}$

The real wage is always first-best with an idiosyncratic shock. The expected gain from indexation and the total expected utility from the contract are therefore independent of idiosyncratic uncertainty.

Given the parties' bargaining strengths, the employer's expected real profit from the long contract is $\Pi_{\ell}(c)=2-2 c L$. Accordingly, the constrained Pareto frontier with a long contract is given by $\left(V_{\ell}(c), \Pi_{\ell}(c)\right)$, where $c \in(0,1 / L)$.

\footnotetext{
14 The formal proofs are similar to the proofs that nominal uncertainty increases the expected gain from backpay and decreases the total expected utility from an extended short contract (note 11), and that idiosyncratic uncertainty decreases the expected gain from backpay (note 12). Relative uncertainty decreases the total expected utility from a long contract, since it decreases not only the expected gain from indexation, but also the expected utility from an unindexed contract.
} 


\section{Extended Short Contract versus Long Contract}

For a given distribution of bargaining powers, the employer's expected real profit is the same with the two forms of contract, i.e., $\Pi_{s}(c)=\Pi_{\ell}(c)$. The first two terms in the workers' expected utility are also the same. It follows that whether the constrained Pareto frontier for an extended short contract or for a long contract dominates is determined by the sign of $V_{s}(c)-V_{\ell}(c)=D$, where

$$
D \equiv\left(\phi_{\delta}+\phi_{\nu}\right) \underset{\epsilon}{\mathrm{E}} \ln \left[\frac{\phi_{\delta}+\phi_{\nu}}{\phi_{\delta}+\phi_{\nu}(1+\epsilon)}\right]-\left(\phi_{\alpha}+\phi_{\beta}+\phi_{\nu}\right) \underset{\epsilon}{\mathrm{E}} \ln \left[\frac{\phi_{\alpha}+\phi_{\beta}+\phi_{\nu}}{\left(\phi_{\alpha}+\phi_{\nu}\right)(1+\epsilon)+\phi_{\beta}}\right]
$$

is the difference between the benefit of backpay for an extended short contract and the benefit of wage indexation for a long contract. Since the benefits of backpay and of wage indexation are independent of the bargaining powers, the difference between them is also independent of the bargaining powers. In the special case that the benefits are equal, then $D=0$ and the constrained Pareto frontiers for an extended short contract and for a long contract are identical. The two contract forms are therefore Pareto equivalent. If the benefit of backpay exceeds the benefit of wage indexation, then $D>0$ and the constrained Pareto frontier for an extended short contract lies fully outside the constrained Pareto frontier for a long contract, in which case an extended short contract Pareto dominates. On the other hand, if the benefit of backpay is less than the benefit of wage indexation, then $D<0$ and the constrained Pareto frontier for an extended short contract lies fully inside the constrained Pareto frontier for a long contract, in which case a long contract Pareto dominates.

Bearing in mind that the gain of expected utility from the optimal backpay decreases with idiosyncratic risk and is independent of relative risk, and that the gain of expected utility from the optimal indexation decreases with relative risk and is independent of idiosyncratic risk, it follows that there is a positive relation between the levels of idiosyncratic and relative risk for which $D=0$.

Although the model has assumed that each type of shock occurs with a positive probability, it is worthwhile to consider which contract form would Pareto dominate in the absence of real uncertainty. To do this, let us assume that there is no real uncertainty (with the other types of uncertainty being present). If idiosyncratic and relative shocks happen to be equally frequent, then the gain of expected utility from the optimal backpay would be identical to the gain of expected utility from the optimal wage indexation at all levels of 
nominal uncertainty. That is, $D=0$ and the two contracts forms are Pareto equivalent. If there is less idiosyncratic than relative risk, then $D>0$ and an extended short contract would Pareto dominate; if there is more idiosyncratic than relative risk, then $D<0$ and a long contract would Pareto dominate. These situations are illustrated in Figure 1, where the $D=0$ locus is the straight $45^{\circ}$ line starting at the origin.

In the presence of real uncertainty, the tradeoff between idiosyncratic and relative risk on the $D=0$ locus is more complicated, and the ranking of the contracts depends on the frequencies of all four types of shocks. It is straightforward, though, to determine how real uncertainty affects the $D=0$ locus. Since that uncertainty does not affect the gain of expected utility from the optimal backpay in an extended short contract, but has a positive effect on the gain of expected utility from the optimal wage indexation in a long contract, real uncertainty reduces the attractiveness of a contract extension. Consequently, the $D=0$ locus moves upward with the level of real uncertainty and it lies completely above the $45^{\circ}$ line. The locus, which is no longer a straight $45^{\circ}$ line, is illustrated in Figure 2. Clearly, a necessary condition for an extended short contract to Pareto dominate is that relative uncertainty exceeds idiosyncratic uncertainty.

The fact that $\phi_{\beta}>\phi_{\delta}$ on the $D=0$ locus immediately implies that $\phi_{\alpha}+\phi_{\beta}+\phi_{\nu}>\phi_{\delta}+\phi_{\nu}$. Thus, the probability of a wage change due to indexation in a long contract exceeds the probability of a wage change due to backpay in an extended short contract. On the $D=0$ locus, therefore, conditional on the occurrence of a wage change, the expected gain from indexation in a long contract is less than the expected gain from backpay in an extended short contract. That is,

$$
\begin{gathered}
\underset{\epsilon}{\mathrm{E}} \ln \left[\frac{\phi_{\delta}+\phi_{\nu}}{\phi_{\delta}+\phi_{\nu}(1+\epsilon)}\right]>\underset{\epsilon}{\mathrm{E}} \ln \left[\frac{\phi_{\alpha}+\phi_{\beta}+\phi_{\nu}}{\left(\phi_{\alpha}+\phi_{\nu}\right)(1+\epsilon)+\phi_{\beta}}\right] \\
\Leftrightarrow \underset{\epsilon}{-\mathrm{E}} \ln \left(1+\frac{\phi_{\nu} \epsilon}{\phi_{\delta}+\phi_{\nu}}\right)>-\underset{\epsilon}{\mathrm{E}} \ln \left[1+\frac{\left(\phi_{\alpha}+\phi_{\nu}\right) \epsilon}{\phi_{\alpha}+\phi_{\beta}+\phi_{\nu}}\right] .
\end{gathered}
$$

Since $\epsilon$ is a random variable with zero mean, this again implies that

$$
\begin{aligned}
\frac{\phi_{\nu}}{\phi_{\delta}+\phi_{\nu}}>\frac{\phi_{\alpha}+\phi_{\nu}}{\phi_{\alpha}+\phi_{\beta}+\phi_{\nu}} \\
\Leftrightarrow \frac{\phi_{\beta}}{\phi_{\delta}}>1+\frac{\phi_{\alpha}}{\phi_{\nu}}
\end{aligned}
$$

on the $D=0$ locus. 
Consequently, the necessary condition for the Pareto dominance of an extended short contract can be strengthened. In the presence of real uncertainty, (9) shows that in order for an extended short contract to Pareto dominate, it is necessary that relative uncertainty exceeds idiosyncratic uncertainty by so much that the ratio of relative to idiosyncratic uncertainty is greater than one plus the ratio of real to nominal uncertainty.

By the same logic, in the presence of real uncertainty, a sufficient condition for a long contract to Pareto dominate is that (9) is violated by the shock frequencies. Thus, a long contract always Pareto dominates a short contract if the ratio of relative to idiosyncratic uncertainty is at most equal to one plus the ratio of real to nominal uncertainty. In particular, a long contract would Pareto dominate in the absence of either relative or nominal uncertainty (with the other types of uncertainty being present). The reason is that if there is no relative uncertainty, then full indexation maximizes the expected gain from indexation and is first-best, while if there is no nominal uncertainty, then backpay cannot provide any reduction in risk.

The higher the level of nominal uncertainty, the greater are both the extent of backpay and the extent of wage indexation, and the more is gained from the ability of the optimal backpay and the optimal wage indexation to reduce the riskiness of the workers' real pay. In the case of an extended short contract, the gain comes at the expense of an increase in the undesired exposure to idiosyncratic shocks, while in the case of a long contract, the gain comes at the expense of an increase in the undesired insulation from relative shocks. If $\phi_{\beta} / \phi_{\delta}=1+\phi_{\alpha} / \phi_{\nu}$, the conditional gain of expected utility is the same for backpay and for indexation, and an (infinitesimal) increase in nominal uncertainty does not affect $D$ since it leads to the same additional gain from the optimal backpay as from the optimal wage indexation. However, if $\phi_{\beta} / \phi_{\delta}>1+\phi_{\alpha} / \phi_{\nu}$ (which is the case on the $D=0$ locus), the conditional gain of expected utility is larger for backpay than for indexation, and an increase in nominal uncertainty increases $D$ since it leads to a larger gain from the risk-reducing capacity of the optimal backpay than from the risk-reducing capacity of the optimal wage indexation. As a consequence, contract extensions become more attractive so that the $D=0$ locus moves downward with the level of nominal uncertainty. ${ }^{15}$

\footnotetext{
15 Appendix B provides formal proof of the effect of nominal uncertainty on the $D=0$ locus.
} 


\section{Conclusion}

This paper has demonstrated that the advantage of concluding a shorter contract that may later be extended, over immediately concluding a longer contract, depends on the prevalence of the different types of uncertainty in the economy. Thus, concluding and later extending a short contract Pareto dominates at high levels of relative and nominal uncertainty, while immediately concluding a longer contract Pareto dominates at high levels of real and idiosyncratic uncertainty.

The paper has also characterized the optimal backpay for the holdout period. It has shown that backpay cannot modify how real and relative uncertainty affect a worker's real income. However, backpay can be instrumental in reducing the negative impact of nominal uncertainty on a worker's real income, but only at the cost of increasing the worker's exposure to idiosyncratic uncertainty. The optimal backpay therefore increases with the missed pay during the extension, with the backpay for a given amount of missed pay increasing with the level of nominal uncertainty and decreasing with the level of idiosyncratic uncertainty.

An important issue for future research would be to examine how allowing for extension of labor contracts would affect the aggregate dynamics of macroeconomic models in which labor contracts play a pivotal role. Specifically, since the backpay does not completely eliminate the effect of nominal uncertainty on a worker's total real pay during the extension period, the effects of nominal shocks would likely last longer when contract extensions are possible than when they are not. 


\section{Appendix A}

\section{First-Best Real Pay in the Second Period}

Let $f_{\alpha}(\alpha)$ denote the first-best real pay for the worker in the second period in terms of $x$ if the shock is real, $f_{\beta}(\beta)$ if the shock is relative, $f_{\delta}(\delta)$ if the shock is idiosyncratic, and $f_{\nu}(\nu)$ if the shock is nominal. Also, let $f(0)$ denote the first-best real pay if there is no shock. Then a worker's expected utility is

$$
\begin{aligned}
& \ln c+\phi_{\alpha} \underset{\alpha}{\mathrm{E}} \ln f_{\alpha}(\alpha)+\phi_{\beta} \underset{\beta}{\mathrm{E}} \ln f_{\beta}(\beta)+\phi_{\delta} \underset{\delta}{\mathrm{E}} \ln f_{\delta}(\delta) \\
& +\phi_{\nu} \underset{\nu}{\mathrm{E}} \ln f_{\nu}(\nu)+\left(1-\phi_{\alpha}-\phi_{\beta}-\phi_{\delta}-\phi_{\nu}\right) \ln f(0) .
\end{aligned}
$$

Since $f_{\beta}(\beta) /(1+\beta)$ is the employer's real cost in terms of $y$ of paying the worker $f_{\beta}(\beta)$ of $x$, the first-best constraint is

$$
\begin{aligned}
& \phi_{\alpha} \underset{\alpha}{\mathrm{E}} f_{\alpha}(\alpha)+\phi_{\beta} \underset{\beta}{\mathrm{E}}\left[\frac{f_{\beta}(\beta)}{1+\beta}\right]+\phi_{\delta} \underset{\delta}{\mathrm{E}} f_{\delta}(\delta) \\
& +\phi_{\nu} \underset{\nu}{\mathrm{E}} f_{\nu}(\nu)+\left(1-\phi_{\alpha}-\phi_{\beta}-\phi_{\delta}-\phi_{\nu}\right) f(0)=c .
\end{aligned}
$$

Maximizing (A1) subject to (A2) shows that the unique first-best real pay for a worker is given by

$$
\begin{aligned}
\frac{1}{f_{\alpha}(\alpha)} & =\mu \quad \text { for all } \alpha \\
\frac{1}{f_{\beta}(\beta)} & =\frac{\mu}{1+\beta} \quad \text { for all } \beta \\
\frac{1}{f_{\delta}(\delta)} & =\mu \quad \text { for all } \delta \\
\frac{1}{f_{\nu}(\nu)} & =\mu \quad \text { for all } \nu \\
\frac{1}{f(0)} & =\mu,
\end{aligned}
$$

where $\mu$ is a positive constant determined to satisfy (A2). Hence, $\mu=1 / c$, and it follows that $f_{\alpha}(\alpha)=f_{\delta}(\delta)=f_{\nu}(\nu)=f(0)=c$ for all realizations of $\alpha, \delta$, and $\nu$, and that $f_{\beta}(\beta)=(1+\beta) c$ for all realizations of $\beta$. Accordingly, the first-best real pay equals $c$ if the shock is real, idiosyncratic, or nominal, as well as if there is no shock, but equals $c(1+\beta)$ if the shock is relative. 


\section{Appendix B}

\section{Effect of Nominal Uncertainty on the $D=0$ Locus}

To determine how nominal risk affects the $D=0$ locus, let $\phi_{\beta}^{0}\left(\phi_{\alpha}, \phi_{\delta}, \phi_{\nu}\right)$ denote the value of $\phi_{\beta}$ for which $D=0$. That is, $\phi_{\beta}^{0}\left(\phi_{\alpha}, \phi_{\delta}, \phi_{\nu}\right)$ is defined by

$$
\left(\phi_{\delta}+\phi_{\nu}\right) \underset{\epsilon}{\mathrm{E}} \ln \left[\frac{\phi_{\delta}+\phi_{\nu}}{\phi_{\delta}+\phi_{\nu}(1+\epsilon)}\right]-\left(\phi_{\alpha}+\phi_{\beta}^{0}+\phi_{\nu}\right) \underset{\epsilon}{\mathrm{E}} \ln \left[\frac{\phi_{\alpha}+\phi_{\beta}^{0}+\phi_{\nu}}{\left(\phi_{\alpha}+\phi_{\nu}\right)(1+\epsilon)+\phi_{\beta}^{0}}\right]=0 .
$$

Differentiate $\phi_{\beta}^{0}$ implicitly with respect to $\phi_{\nu}$,

$$
\frac{\partial D}{\partial \phi_{\nu}}+\frac{\partial D}{\partial \phi_{\beta}} \frac{d \phi_{\beta}^{0}}{d \phi_{\nu}}=0
$$

where the derivatives of $D$ are evaluated at $D=0$. Hence, the sign of $d \phi_{\beta}^{0} / d \phi_{\nu}$ is the opposite of the sign of $\partial D / \partial \phi_{\nu}$. The latter derivative is

$$
\begin{aligned}
\frac{\partial D}{\partial \phi_{\nu}}= & \underset{\epsilon}{\mathrm{E}}\left\{\ln \left[\frac{\phi_{\delta}+\phi_{\nu}}{\phi_{\delta}+\phi_{\nu}(1+\epsilon)}\right]-\frac{\left(\phi_{\delta}+\phi_{\nu}\right)(1+\epsilon)}{\phi_{\delta}+\phi_{\nu}(1+\epsilon)}\right. \\
& \left.-\ln \left[\frac{\phi_{\alpha}+\phi_{\beta}^{0}+\phi_{\nu}}{\left(\phi_{\alpha}+\phi_{\nu}\right)(1+\epsilon)+\phi_{\beta}^{0}}\right]+\frac{\left(\phi_{\alpha}+\phi_{\beta}^{0}+\phi_{\nu}\right)(1+\epsilon)}{\left(\phi_{\alpha}+\phi_{\nu}\right)(1+\epsilon)+\phi_{\beta}^{0}}\right\} .
\end{aligned}
$$

Differentiating the internal function with respect to $\epsilon$ yields

$$
\left\{\frac{1}{\left(\phi_{\delta} / \phi_{\nu}+1+\epsilon\right)^{2}}-\frac{1}{\left[\phi_{\beta}^{0} /\left(\phi_{\alpha}+\phi_{\nu}\right)+1+\epsilon\right]^{2}}\right\} \epsilon .
$$

The curled brackets have the same sign as

$$
\frac{\phi_{\beta}^{0}}{\phi_{\alpha}+\phi_{\nu}}-\frac{\phi_{\delta}}{\phi_{\nu}}=\frac{\phi_{\delta}}{\phi_{\alpha}+\phi_{\nu}}\left(\frac{\phi_{\beta}^{0}}{\phi_{\delta}}-1-\frac{\phi_{\alpha}}{\phi_{\nu}}\right)
$$

which is positive since $\phi_{\beta} / \phi_{\delta}>1+\phi_{\alpha} / \phi_{\nu}$ on the $D=0$ locus. It follows that the internal function decreases in $\epsilon$ if $\epsilon<0$ and increases in $\epsilon$ if $\epsilon>0$. Since the internal function vanishes for $\epsilon=0$, it can be concluded that the internal function is positive for $\epsilon \neq 0$. Accordingly, $\partial D / \partial \phi_{\nu}>0$, implying that $d \phi_{\beta}^{0} / d \phi_{\nu}<0$ so that the $D=0$ locus moves downward with nominal uncertainty. 


\section{References}

Christofides, Louis N. "The Interaction between Indexation, Contract Duration and Noncontingent Wage Adjustment." Economica 57 (August 1990): 395-409.

Christofides, Louis N. and Wilton, David A. "The Determinants of Contract Length." Journal of Monetary Economics 12 (June 1983): 309-319.

Christofides, Louis N. and Peng, Chen. "Contract Duration and Indexation an a Period of Real and Nominal Uncertainty." Labour Economics 13 (February 2006): 61-86.

Cramton, Peter C. and Tracy, Joseph S. "Strikes and Holdouts in Wage Bargaining: Theory and Data." American Economic Review 82 (March 1992): 100-21.

Cramton, Peter C. and Tracy, Joseph S. "The Determinants of U.S. Labor Disputes." Journal of Labor Economics 12 (April 1994): 180-209.

Danziger, Leif. "Real Shocks, Efficient Risk Sharing, and the Duration of Labor Contracts." Quarterly Journal of Economics 103 (May 1988): 435-440.

Danziger, Leif and Neuman, Shoshana. "Delays in Renewal of Labor Contracts: Theory and Evidence." Journal of Labor Economics 23 (April 2005): 341-371.

Dye, Ronald A. "Optimal Length of Labor Contracts." International Economic Review 26 (February 1985): 251-270.

Ehrenberg, Ronald G., Danziger, Leif and San, Gee: "Cost-of-Living Adjustment Clauses in Union Contracts." Research in Labor Economics 6 (1984): 1-63.

Gray, Jo Anna. "On Indexation and Contract Length." Journal of Political Economy 86 (February 1978): 1150-1175.

$\mathrm{Gu}$, Wulong and Kuhn, Peter. "A Theory of Holdouts in Wage Bargaining." American Economic Review 88 (June 1998): 428-49.

Fehr, Ernst and Falk, Armin. "Wage Rigidity in Competitive Incomplete Contract Market." Journal of Political Economy 107 (February 1999): 106-134.

Harris, Milton and Holmstrom, Bengt. "On the Duration of Agreements." International Economic Review 28 (June 1987): 389-405.

Holden, Steinar. "Wage Bargaining and Nominal Rigidities." European Economic Review 38 (May 1994): 1021-39.

Holden, Steinar. "Wage Bargaining, Holdout, and Inflation." Oxford Economic Papers 49 (April 1997): 235-255. 
Houba, Harold and Bolt, Wilko. "Holdouts, Backdating and Wage Negotiations." European Economic Review 44 (October 2000): 1783-1800.

Murphy, Kevin. J. "Determinants of Contract Duration in Collective Bargaining Agreements." Industrial and Labor Relations Review 45 (January 1992): 352-365.

Murphy, Kevin. J. "What Effect Does Uncertainty Have on the Length of Labor Contracts?" Labour Economics 7 (March 2000): 181-201.

Rich, Robert and Tracy, Joseph. "Uncertainty and Labor Contract Durations." Review of Economics and Statistics 86 (February 2004): 270-287.

Van Ours, Jan C. and Van de Wijngaert, Rob F. "Holdouts and Wage Bargaining in The Netherlands." Economics Letters 53 (October 1996): 83-88.

Van Ours, Jan C. "The Cyclical Behavior of Holdout Durations." Economics Letters 62 (March 1999): 365-370.

Vroman, Susan B. "Inflation Uncertainty and Contract Duration." Review of Economics and Statistics 71 (November 1989): 677-681.

Wallace, Frederick H. and Blanco, Herminio. "The Effects of Real and Nominal Shocks on Union-Firm Contract Duration." Journal of Monetary Economics 27 (June 1991): 361-380.

Wallace, Frederick H. "The Effects of Shock Size and Type on Labor-Contract Duration." Journal of Labor Economics 19 (July 2001): 658-681. 